\title{
On the Acceptance of Gain Sharing Methods in Supply Chain Collaboration
}

Citation for published version (APA):

Grigoriev, A., Jung, V., Peeters - Rutten, M., \& Vredeveld, T. (2017). On the Acceptance of Gain Sharing Methods in Supply Chain Collaboration. Maastricht University, Graduate School of Business and Economics. GSBE Research Memoranda No. 024 https://doi.org/10.26481/umagsb.2017024

Document status and date:

Published: 10/10/2017

DOI:

10.26481/umagsb.2017024

Document Version:

Publisher's PDF, also known as Version of record

\section{Please check the document version of this publication:}

- A submitted manuscript is the version of the article upon submission and before peer-review. There can be important differences between the submitted version and the official published version of record.

People interested in the research are advised to contact the author for the final version of the publication, or visit the DOI to the publisher's website.

- The final author version and the galley proof are versions of the publication after peer review.

- The final published version features the final layout of the paper including the volume, issue and page numbers.

Link to publication

\footnotetext{
General rights rights.

- You may freely distribute the URL identifying the publication in the public portal. please follow below link for the End User Agreement:

www.umlib.nl/taverne-license

Take down policy

If you believe that this document breaches copyright please contact us at:

repository@maastrichtuniversity.nl

providing details and we will investigate your claim.
}

Copyright and moral rights for the publications made accessible in the public portal are retained by the authors and/or other copyright owners and it is a condition of accessing publications that users recognise and abide by the legal requirements associated with these

- Users may download and print one copy of any publication from the public portal for the purpose of private study or research.

- You may not further distribute the material or use it for any profit-making activity or commercial gain

If the publication is distributed under the terms of Article $25 \mathrm{fa}$ of the Dutch Copyright Act, indicated by the "Taverne" license above, 


\section{Maastricht University}

Alexander Grigoriev,

Verena Jung, Marianne Peeters,

Tjark Vredeveld

On the Acceptance of Gain Sharing Methods in Supply Chain Collaboration

$\mathrm{RM} / 17 / 024$

\section{GSBE}

Maastricht University School of Business and Economics

Graduate School of Business and Economics

P.O Box 616

NL- 6200 MD Maastricht

The Netherlands 


\title{
On the Acceptance of Gain Sharing Methods in Supply Chain Collaboration
}

\author{
Alexander Grigoriev, Verena Jung, Marianne Peeters and Tjark Vredeveld
}

Purpose - The purpose of this paper is to investigate the acceptance of different gain sharing methods in practice. In addition, the influence of behavioural aspects on the acceptance of these allocation methods is observed.

Design/methodology/approach - In order to investigate the research question, a behavioural study is conducted in form of online surveys. The online surveys are performed with manufacturers, logistics service providers (LSPs) and retailers from the Dutch fast moving consumer goods (FMCG) industry. Further, a control group consisting of students is used in order to investigate potential cognitive biases of business practitioners.

Findings - Results indicate that the acceptance of a gain sharing method depends on the information availability and cognitive biases. Further, due to a different influence of information availability and varying cognitive biases no gain sharing methods is preferred by all involved parties.

Practical implications -The major barrier for the implementation and the success of a SCC is a fair allocation method which is accepted by all parties involved in the SCC. One practical implication of this study to overcome this barrier is to provide each party individually all relevant information.

Originality/value - The study extends the work by Cruijssen et al. (2007a) as well as Leng and Parlar (2009) and provides novel insights in the understanding of the acceptance of gain sharing methods through the investigation of the acceptance levels and the integration of behavioural decisionmaking literature.

\section{Introduction}

Due to a constantly growing competition among organizations and higher customer expectations, in the last decades, companies started to realize the need for supply chain collaboration (SCC) (Cao and Zhang, 2011; Lambert et al. 1996; Simatupang and Sridharan, 2002). Nowadays, SCC is a widely discussed topic which can be defined as "two or more independent companies work jointly to plan and execute [...] operations with greater success than when acting in isolation" (Simatupang and Sridharan, 2002).

According to Defryn et al. (2016), the main motivation for parties to start a SCC is the lower coalition costs compared to their stand-alone costs. This is stressed by the research by Jung et al. (2017a; 2017b). They interviewed companies from the Dutch fast moving consumer goods (FMCG) industry to investigate relevant drivers and resistors for starting SCCs. In their study "cost reduction" is the dominant motivation factor for parties to start SCCs. By reducing costs through SCC, a so-called coalition gain is achieved. The coalition gain represents the difference between the coalition costs and the stand-alone costs. One main challenge in collaborations is the division of the coalition gain among the parties (Defryn et al., 2016; Vanovermeire et al., 2014b). According to Cruijssen et al. (2007a), in horizontal collaborations the fair distribution of the coalition gain even represents the 
major barrier for the implementation of SCCs. In the context of vertical SCC, Leng and Parlar (2009) confirm the importance of a fair allocation method for the parties to stay in the SCC. If one party is not satisfied with its allocated share or has the feeling that it does not get a fair portion of the coalition gain, future SCCs are less likely to occur (Jap, 2001). Cruijssen et al. (2007b) also mention that mistrust about the fairness of the applied allocation method caused already many failures of SCCs. This is stressed by Cruijssen (2012) who states that having a fair allocation method, which is also perceived as fair by the parties, is essential for a successful SCC. In order to solve this problem, researchers developed different so-called gain sharing methods to allocate the coalition gain among all parties participating in the collaboration (Vanovermeire et al., 2014b). The general idea of these gain sharing methods is to distribute the gains in such a way that everyone is satisfied to ensure the establishment and sustainability as well as to realize the potential of the SCC (Liu et al., 2010). Although, Cruijssen et al. (2007a) as well as Leng and Parlar (2009) outline the importance of the acceptance of a gain sharing method by all parties for the implementation and the success of a SCC, until now the actual acceptance levels of gain sharing methods have not been investigated.

Therefore, in this paper the work by Cruijssen et al. (2007a) as well as the work by Leng and Parlar (2009) is extended through the investigation of the acceptance of selected gain sharing methods in practice.

Moreover, aspects that might have an influence on the acceptance levels of these gain sharing methods are observed. For a long time, the predominant assumption in economics was that human beings are rational thinking agents, which implies the decisions are made in a rational and consistent way (Sterman, 1989). However, human beings are bounded due to limitations in available time, information and cognitive capabilities (Simon, 1979). They tend to rely on heuristics or cognitive biases to deal with complex problems (Schenk, 2011). Until now, limited research has been published in the logistics and supply chain management (SCM) literature dealing with the influence of human behaviour, judgment and decision-making. However, decision-makers are human beings. To ensure practical validity it is necessary to incorporate behavioural research in studies (Tokar, 2010). This is stressed by Mantel et al. (2006) who outline the greater understanding of decisions made in SCM by integrating decision-making behaviour literature with SCM literature. In this paper, the behavioural decision-making literature is considered by investigating the influence of different behavioural aspects on the acceptance of gain sharing methods.

The remainder of this paper is structured as follows. In Section 2, different gain sharing methods are outlined and the behavioural decision-making literature is discussed. Next, the acceptance of selected gain sharing methods as well as the influence of behavioural aspects on the acceptance levels of these allocation methods is investigated through a behavioural study. The research methodology is further detailed in Section 3. In Section 4, the statistical analysis and the results are presented, followed by a discussion in Section 5. Moreover, the contribution to the SCM literature is explained, valuable practical implications are provided and directions of further research are outlined.

\section{Literature Review}

\subsection{Gain Sharing Methods}

In literature two kinds of allocation methods exist, gain sharing methods and cost allocation methods. Gain sharing methods are used if the gain is split among the parties, whereas, cost allocation methods are applied if the total costs of the SCC are divided among the parties (Defryn et 
al., 2016). Until now a wide range of possible allocation methods ranging from straightforward rules of thumbs to game theory based methods have been proposed and applied either as a gain sharing method or a cost allocation method (Vanovermeire et al., 2014a).

One of the most well-known game-theoretical methods is the Shapley value, introduced by Shapley (1953). The Shapley value has already been applied as a gain sharing method by Vanovermeire et al. (2014b) to a horizontal SCC in the FMCG industry. In addition, Frisk et al. (2010) used the Shapley value to allocate the costs in the forest transportation industry. Another well-known gametheoretical allocation method is the Nucleolus, introduced by Schmeidler (1969). The Nucleolus has been applied as a gain sharing and a cost allocation method as well. Vanovermeire et al. (2014a) discuss the Nucleolus as a cost allocation method and apply it to collaborative transport settings. Liu et al. (2010) apply this method to a SCC between Less-Than-Truckload carriers in order to allocate the collaborative gain. Tijs and Driessen (1986) discuss an allocation method that first divides the costs in a separable and non-separable part. The separable part is directly linked and assigned to a specific party. The remaining costs, the non-separable part, have to be divided among the parties. Tijs and Driessen (1986) mention different ways of how the non-separable part of the costs can be allocated. They discuss the equal charge method (ECM), the alternative cost avoided method (ACAM) and the separable cost remaining benefits (SCRB). They also introduce a new method, the cost gap method (CGM). Furthermore, Frisk et al. (2010) introduce and apply the equal profit method (EPM), where the maximum difference between the relative savings of two parties is minimized. Liu et al. (2010) propose an allocation method which is called the weighted relative savings model (WRSM) and apply it next to the Shapley value to the SCC between Less-Than-Truckload carriers.

The above mentioned allocation methods are all game-theoretical based methods. In practice simple methods are often preferred, which is most likely due to the fact that game-theoretical allocation methods are more difficult to understand, more complicated to compute and more data are required (Leng and Parlar, 2005). One simple method is the equal allocation of the coalition gain among the parties (Jap, 2001). Next to the equal allocation, methods where the weight for each party is determined based on e.g. the volume (i.e. the number of pallets, the total weight...) are often used in practice. Another possibility is to determine the weight according to the stand-alone costs (Vanovermeire et al., 2014a).

\subsection{Behavioural Decision-Making}

For a long time, the predominant assumption in economics was that humans are rational thinking agents. However, Simon (1979) describes a bound on rational decision-making due to limitations of available time, information and cognitive capabilities of the decision-makers. Although people think that they are rational thinking creatures, our thinking, our memory and also our decision-making are influenced by cognitive biases. Until now, a wide range of cognitive biases have been identified. Among these is the recency bias, where people tend to put more weight on the latest information they get (Hallowell and Gambrese, 2010). Another example is the so-called salience bias, where human beings tend to focus on the most easily-recognizable items or information of a concept and ignore the once which are not that visible (Schenk, 2011). The choice-supportive bias is a bias, where people tend to feel positive about something they choose, even if the choice has a flaw (Mather and Johnson, 2000). As a final example, the framing effect bias is named. According to de Martino et al. (2006), human beings are remarkable vulnerable to the manner in which the options are presented, which is the so-called framing effect. Therefore, when facing consequentially identical decision problem people's decisions may be contrary depending on how the options are presented; in a positive, in terms of gains, or in a negative, in terms of losses, "frame". A popular example is the 
"Asian disease problem" described by Tversky and Kahneman (1981). They find out that decisionmakers tend to avoid risk when information on gains and losses are presented in a positive frame but the same decision-maker is willing to take a greater risk once the information is presented in a negative frame.

\section{Research Procedure}

In this paper, a behavioural study in form of online surveys is performed in order to investigate the acceptance levels of different gain sharing methods. Moreover, the influence of behavioural aspects on the acceptance levels of these allocation methods is observed. Behavioural studies are a wellestablished research method for studying human factors (Bendoly et al., 2005).

The research procedure is divided into four different steps. In Table 1, the main aspects for each of these steps are outlined. 
Table 1: Research procedure

\begin{tabular}{|c|c|c|c|}
\hline & Procedure & & Reference \\
\hline \multirow[t]{7}{*}{ Step 1} & \multirow[t]{7}{*}{ Variable Selection } & Independent Variables & Section 3.1 \\
\hline & & \multirow{4}{*}{\multicolumn{2}{|c|}{$\begin{array}{l}\text { Gain sharing method (Nucleolus, Shapley value, } \\
\text { Weighted charge method - Power/Initiator, ECM) } \\
\text { Information availability (Phase 1, Phase 2, Phase 3) } \\
\text { Perspective (Manufacturer, LSP, Retailer) }\end{array}$}} \\
\hline & & & \\
\hline & & & \\
\hline & & & \\
\hline & & \multicolumn{2}{|l|}{ Dependent Variable } \\
\hline & & \multicolumn{2}{|l|}{ Acceptance } \\
\hline Step 2 & Data collection & $\begin{array}{l}\text { Participants evaluate whether to accept or } \\
\text { reject a certain gain share for each of the } \\
\text { five gain sharing methods in each of the } \\
\text { three phases } \\
\text { - Only outcomes (ordered from the lowest to } \\
\text { the highest) are presented, it is not } \\
\text { mentioned which method is applied }\end{array}$ & Section 3.2 \\
\hline
\end{tabular}

\begin{tabular}{|c|c|c|c|}
\hline Step 3 & $\begin{array}{l}\text { Population and } \\
\text { Sample Selection }\end{array}$ & $\begin{array}{l}\text { Business Practitioners } \\
\text { Population: Companies from the Dutch FMCG } \\
\text { industry and participants in a specific logistics } \\
\text { competition } \\
\text { Sample Size: } 4 \text { manufacturers, } 4 \text { LSPs, } 4 \text { retailers } \\
\text { Control Group } \\
\text { Population: Students from Maastricht University } \\
\text { Sample Size: } 51 \text { bachelor and master students (17 } \\
\text { manufacturers, } 17 \text { LSPs, } 17 \text { retailers) }\end{array}$ & Section 3.3 \\
\hline Step 4 & Data Analysis & $\begin{array}{l}\text { Research Question } \\
\text { What are the acceptance levels of different gain } \\
\text { sharing methods and what is the influence of } \\
\text { different behavioral decision-making aspects on the } \\
\text { acceptance levels of these allocation methods? } \\
\text { Analysis Tool } \\
\text { Binary logistic regression; binary logistic regression } \\
\text { with penalized maximum likelihood estimation } \\
\text { Independent Variables } \\
\text { Gain sharing method (Method): Categorical variable } \\
\text { - Baseline: Nucleolus } \\
\text { Information availability (Phase): Categorical variable } \\
\text { - Baseline: Phase } 1 \\
\text { Perspective (Type): Categorical variable - Baseline: } \\
\text { Manufacturer } \\
\text { Dependent Variable } \\
\text { Acceptance: Binary variable }\end{array}$ & Section 3.4 \\
\hline
\end{tabular}




\subsection{Variable Selection}

In the study, the influence of three aspects - gain sharing method, information availability and perspective - on the acceptance of different gain sharing methods is investigated. These aspects are outlined in more detail in the next sections.

\subsubsection{First Aspect: Gain Sharing Method}

First, the influence of the gain sharing method, which represents the first variable, is investigated. The gain sharing method determines the gain which is assigned to each party. As these differ among the gain sharing methods, the level of acceptance of the methods are most likely different which might uncover possible cognitive biases. In this research, the focus is on four different gain sharing methods; the Shapley value, the Nucleolus and two methods based on separable and non-separable costs, the weighted charge method (WCM) and the ECM. For the WCM two different weights are chosen. Therefore, in total five different gain sharing methods are investigated. The first two allocation methods are well-known game-theoretical based methods and the most preferred methods in theory (Moulin, 1988). The last two allocation methods are most similar to what is already used in practice. This is based on a preliminary study, which has been conducted with 20 companies from the Dutch FMCG industry, the industry under consideration in the survey. In Appendix $A$, the questionnaire of this preliminary study is shown and information about data collection is provided.

\section{Shapley Value}

For the Shapley value the formation of the grand-coalition $N$, which includes every party of the SCC, can be seen as a sequential process, where the parties of the SCC enter one by one. For every party $i$, the value is defined as the average marginal contribution of the party to every possible sub-coalition $S$ of the grand-coalition containing this party. The Shapley value is based on the four axioms formulated by Shapley (1953) and can be computed by:

$$
x_{i}=\sum_{S \subset N \backslash i} \frac{|S| !(|N|-|S|-1) !}{|N| !} *(c(S \cup i)-c(S))
$$

$x_{i}=$ the allocated gain for party $i$

$N=$ the grand-coalition (all parties included)

$S=$ a sub-coalition

$|N|,|S|=$ the number of parties in a grand-coalition and sub-coalition, respectively

$c(S)=$ the costs of sub-coalition $S$

\section{Nucleolus}

The Nucleolus (Schmeidler, 1969) is based on the idea to minimize the maximum excess. The excess is the gain the parties in a sub-coalition $S$ obtain if they exit the grand-coalition $N$. For a sub-coalition $S$ given an allocation $x$ the excess is denoted as:

$$
e(x, S)=c(S)-\sum_{i \in S} x_{i}
$$

$e(x, S)=$ the excess for a sub-coalition $S$ given an allocation $x$ 
$S=$ a sub-coalition

$x_{i}=$ the allocated gain for party $i$

$c(S)=$ the costs of the sub-coalition $S$

\section{Weighted Charge Method}

The WCM is based on the idea of Tijs and Driessen (1986) that the costs are at first split in a separable $\left(m_{i}=c(N)-c(N \backslash i)\right)$ and a non-separable part $\left(c(N)-\sum_{j} m_{j}\right)$. The non-separable part is divided among the parties according to some specific weight $w_{i}$. The allocation portion for a party $i$ is then computed as follows:

$$
x_{i}=m_{i}+\left(c(N)-\sum_{j} m_{j}\right) * w_{i}
$$

$x_{i}=$ the allocated gain for party $i$

$m_{i}=$ the separable part of the gain for party $i$ and $j$, respectively

$N=$ the grand-coalition (all parties included)

$c(N\}=$ the costs of the grand-coalition $N$

$w_{i}=$ specific weight for party $i$

Based on the preliminary study (Appendix A) two different kinds of weights have been identified, one based on the power position and one based on the initiator. In the Dutch FMCG industry the retailer is the most powerful party. Therefore, the highest weight with $w_{r}=0.5$ is assigned to the retailer. In comparison to the manufacturer the LSP is more powerful, therefore, a weight of $w_{l}=0.3$ is assigned to the LSP and the rest $w_{m}=0.2$ is assigned to the manufacturer. Further, in the Dutch FMCG industry often the LSP initiates to start the SCC. Therefore, the highest weight with $w_{l}=0.4$ is assigned to the LSP. The rest is equally split among the manufacturer and the retailer.

\section{Equal Charge Method}

The ECM is also based on the idea of Tijs and Driessen (1986). In contrast to the WCM, the nonseparable part is equally distributed among the parties. Therefore, the total amount allocated to each party $i$ is:

$$
x_{i}=m_{i}+\frac{c(N)-\sum_{j} m_{j}}{|N|}
$$

$x_{i}=$ the allocated gain for party $i$

$m_{i}=$ the separable part of the gain for party $i$ and $j$, respectively

$N=$ the grand-coalition (all parties included)

$|N|=$ the number of parties in a grand-coalition

$c(N)=$ the costs of the grand-coalition $N$

\subsubsection{Second Aspect: Information Availability}

Second, the influence of the information availability, which represents the second variable, is investigated. This behavioural decision-making aspect refers to the limitation of available information 
outlined by Simon (1979) in the context of bounded rationality. Human beings make their decisions based on cognitive biases when available information is limited (Sterman, 1989). In order to investigate the influence of available information, three different phases are developed, where the amount of information increases with each phase. In the first phase, the participants only get the information about their own financial consequences. This includes information about their expected benefits, the costs related to the SCC and the resulting expected profit, which is equal to the contribution they make to the coalition gain, see Table 2 . Moreover, they get the information about the gain they will get according to each of the five different gain sharing methods, see Table 3 . In the second phase, the participants also get the information about the financial consequences of the other parties in the supply chain. In the last phase, market information for each party of the SCC is included. Here information about the market share, the products and the importance of a relationship with the party is included, see Figure 1.

Table 2: Information about the financial consequences after a five year SCC

\begin{tabular}{llll}
\hline & Manufacturer/ Party A & LSP/ Party B & Retailer/ Party C \\
\hline Benefits & $80,000 €$ & $50,000 €$ & $250,000 €$ \\
Costs & $85,000 €$ & $10,000 €$ & $80,000 €$ \\
Profits & $-5,000 €$ & $40,000 €$ & $170,000 €$ \\
\hline
\end{tabular}

Table 3: Gain assigned to the different parties according to the gain sharing methods

\begin{tabular}{llcc}
\hline & Manufacturer/ Party A & LSP/ Party B & Retailer/ Party C \\
\hline Nucleolus & $4,333.33 €$ & $55,333.33 €$ & $145,333.33 €$ \\
Shapley & $36,333.33 €$ & $61,833.33 €$ & $106,833.33 €$ \\
WCM-Power & $41,000.00 €$ & $61,500.00 €$ & $102,500.00 €$ \\
WCM-Initiator & $61,500.00 €$ & $82,000.00 €$ & $61,500.00 €$ \\
ECM & $68,333.33 €$ & $68,333.33 €$ & $68,333.33 €$ \\
\hline
\end{tabular}

\section{Market Information}

Party C/ Retailer is the biggest player on the market with a market share of $25 \%$ and is a member of a union called "Super Unie". Relationships with this party are important

Party B/ LSP is a medium player on the market with a market share of $10 \%$.

Party A/ Manufacturer is based locally (not international) and the goods are relatively easy to substitute. Party A/Manufacturer is not a member of any association or union of parties from the same position in the supply chain.

Figure 1: Market information for each party 


\subsubsection{Third Aspect: Perspective}

Third, the influence of the perspective, which represents the third variable, is investigated. The behavioural study focuses on a vertical SCC between one manufacturer, one LSP and one retailer. Different parties in the SCC have different information and, therefore, most likely show different cognitive biases (Sterman, 1989).

\subsection{Data collection}

For data collection, an online survey is conducted. The strong methodology control is the main reason to use an online survey. In an online survey the order of the questions, the completeness of the answers and the filtering can be controlled by the researcher (Evans and Mathur, 2005). The participants are asked in each phase of information availability and for each of the five gain sharing methods to evaluate whether they would accept or reject the assigned gain. Thereby, the question order from Phase 1 to Phase 3 is necessary in order to observe the influence of available information. The participants only see the outcomes of the gain sharing method but they do not know which method is applied. Therefore, the acceptance of the gain sharing method is investigated through the acceptance of the specific outcome. The outcomes are ranked from the lowest to the highest in order to prevent parties rejecting an outcome which is lower than one before. Another important advantage of the online survey is that participants cannot look ahead like in a mail survey. However, in such a situation the questionnaire might appear to have an endless number of questions which might keep a respondent from continuing the online survey (Evans and Mathur, 2005). In order to prevent this, a graphical progress indicator is used. The predetermined order and the prevention of looking ahead to later questions reduce the survey bias. Moreover, through the use of an online survey and not a personal survey or a telephone survey the so-called interview bias is avoided which can always occur when there is a personal contact between the interviewer and the respondent (Evans and Mathur, 2005). The goal of the online survey is to inter alia observe cognitive biases, therefore, the prevention of biases resulting out of the surveys is very important. Furthermore, split samples are used. The online surveys differ per party of the SCC. According to Evans and Mathur (2005), "online surveys are particularly effective when multiple samples are involved".

The online surveys are distributed through a link to the survey URLs in an e-mail. Reminders are sent out to achieve a higher response rate. An example of the online survey can be found in Appendix $B$.

\subsection{Population and Sample Size Selection}

The online surveys are conducted with managers of companies from the Dutch FMCG industry. This industry is selected because of the importance of SCCs for this industry (de Kok et al., 2015). In the FMCG industry it is necessary for parties to collaborate with their supply chain partners. To ensure sustainable SCCs, all parties have to be satisfied with and accept their assigned gain share. The participants are selected from a population of 26 companies participating in a logistic competition in the Netherlands. The sample size is 12 including four manufacturers, four LSPs and four retailers.

Next to this sample of business practitioners, a control group is taken into account. A control group is used for experiments to identify special aspects of the experiment group (Bailey, 2008). In this paper, by using a control group the cognitive biases of the business practitioners outlined in Section 3.1 should be identified. The control group consists of students from Maastricht University. Students are chosen due to their sufficient knowledge to understand the situation but limited experiences in working in the industry. Out of this population, a sample size of 51 students is randomly selected. 
These students are randomly assigned to the three different parties without knowing which role they take. To this end, the manufacturer is replaced by party A, the LSP by party $B$ and the retailer by party $\mathrm{C}$.

\subsection{Data Analysis}

To analyse the acceptance levels of selected gain sharing methods as well as the influence of behavioural aspects, particularly the information availability and cognitive biases, on the acceptance levels of these allocation methods, a binary logistic regression is performed (Hosmer and Lemeshow, 2000). In order to use the logistic regression some data preparations have to be made. The dependent variable is a binary variable getting a value equal to 1 , if the gain is accepted and 0 , otherwise. The three independent variables are all categorical variables. The gain sharing method variable is coded as "Nucleolus", "Shapley", "WCM-Power", "WCM-Initiator" and "ECM". Taken the Nucleolus as a baseline, the gain sharing variable is represented by four binaries. To represent the five different gain sharing methods only four design variables are needed due to an intercept used in the model (Homser and Lemeshow, 2000). Information availability is represented by two variables with Phase 1 designated as the reference phase. The perspective is also represented by two variables and the manufacturer is taken as the reference category.

For the business practitioners, problems with the logistic regression occurred as a consequence of the data pattern known as quasi-complete separation. Quasi-complete separation occurs if the dependent variable of an independent dummy variable is always either equal to 1 or to 0 . As a consequence, the maximum likelihood estimate does not exist. This problem often occurs if a small sample size is used (Allison, 2008) as it is the case for the business practitioners. Therefore, for the business practitioners a binary logistic regression with penalized maximum likelihood estimation is used. The penalized maximum likelihood estimation method has been proposed by Firth (1993) to reduce the bias in maximum likelihood estimates. Heinze and Schemper (2002) show that this method provides a solution for the quasi-complete separation problem. The basic idea of the penalized maximum likelihood estimation method is to introduce a modified score function which removes the bias of the maximum likelihood estimates of the coefficients (Firth, 1993). For a more elaborate explanation of this method, the reader is referred to Firth (1993) and Heinze and Schemper (2002).

Both binary logistic regressions are performed using $R$ (version 3.3.2). For the binary logistic regression with the penalized maximum likelihood estimation method the package logist $f$ and for the normal binary logistic regression the function $g / m()$ is used. The package logist $f$ uses as a default the penalized log likelihood ratio test. As this method is also recommended by Heinze and Schemper (2002) for the binary logistic regression with maximum likelihood estimation, the penalized log likelihood ratio test is used. For the binary logistic regression the Wald test is used as an inferential statistical test which is the default used by the $g / m()$-function.

The data analysis starts with a multicollinearity test. Based on the results of the multicollinearity tests the binary logistic regressions are performed. At first, the influence of all three independent variables on the acceptance levels of different gain sharing methods is investigated. This is followed by the analysis of the influence of aspects on the acceptance level of each party separately. Therefore, three additional logistic regressions, one for the manufacturers, one for the LSPs and one for the retailers, are performed to inter alia identify specific cognitive biases for each party. All logistic regressions are performed for the business practitioners and the control group. Through an extensive comparison between the different logistic regressions, acceptance levels of different parties and behavioural aspects are identified. In Figure 2 an overview of the procedure of the data analysis is presented. 


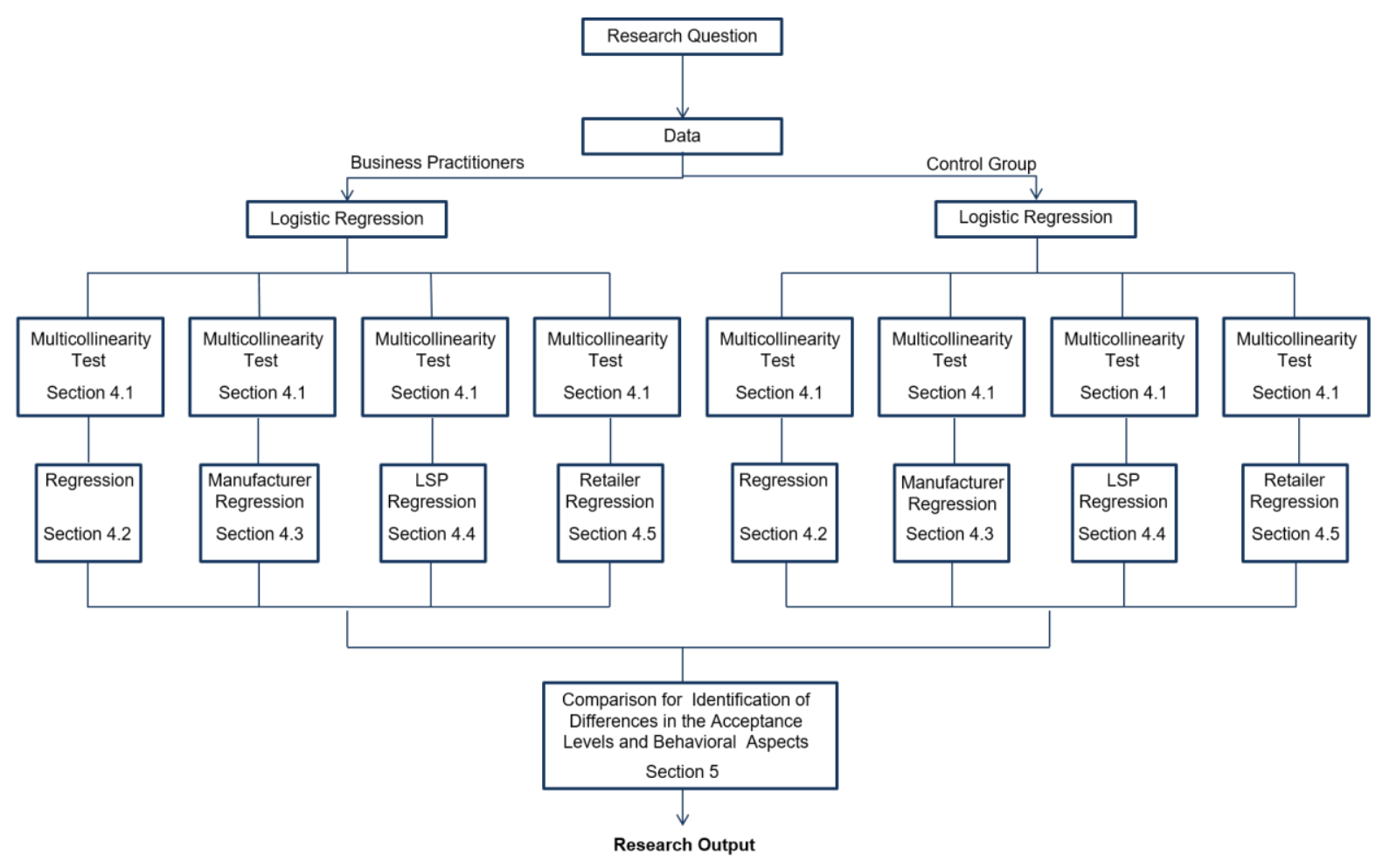

Figure 2: Procedure of the data analysis

\section{Statistical Analysis and Results}

In the following the statistical analysis and the results are presented. At first, the results for the multicollinearity test are presented. This is followed by the outcomes of the logistic regression where the influence of all independent variables on the acceptance levels is observed. Next, the results for each of the three parties separately are shown. As of now, a significance level of $5 \%$ is taken as the standard significance level.

\subsection{Multicollinearity}

One common problem when using multiple independent variables in a logistic regression is the occurrence of correlation among independent variables. When two independent variables are highly correlated, the problem known as multicollinearity occurs. Multicollinearity can seriously distort the interpretation of the model (Greene, 2003). Table 4 shows an example for the correlation matrix of business practitioners' logistic regression. All correlation coefficients have small values $(\leq 0.5)$ indicating no problems with multicollinearity. Appendix $\mathrm{C}$ contains all other correlation matrices. The correlation coefficients for all other logistic regressions are small as well. Therefore, all independent variables are included in the logistic regressions. 
Table 4: Correlation matrix of the regression of the business practitioners

\begin{tabular}{|c|c|c|c|c|c|c|c|c|c|c|c|}
\hline & $\begin{array}{l}\text { Phase } \\
1\end{array}$ & $\begin{array}{l}\text { Phase } \\
2\end{array}$ & $\begin{array}{l}\text { Phase } \\
3\end{array}$ & $\begin{array}{l}\text { Nucleo- } \\
\text { Ius }\end{array}$ & Shapley & $\begin{array}{l}\text { WCM- } \\
\text { Power }\end{array}$ & $\begin{array}{l}\text { WCM- } \\
\text { Initiator }\end{array}$ & ECM & $\begin{array}{l}\text { Manufac- } \\
\text { turer }\end{array}$ & LSP & Retailer \\
\hline Phase 1 & 1.00 & -0.50 & -0.50 & -0.00 & -0.00 & -0.00 & -0.00 & -0.00 & -0.00 & -0.00 & -0.00 \\
\hline Phase 2 & & 1.00 & -0.50 & -0.00 & -0.00 & -0.00 & -0.00 & -0.00 & -0.00 & -0.00 & -0.00 \\
\hline Phase 3 & & & 1.00 & -0.00 & -0.00 & -0.00 & -0.00 & -0.00 & -0.00 & -0.00 & -0.00 \\
\hline Nucleolus & & & & 1.00 & -0.25 & -0.25 & -0.25 & -0.25 & -0.00 & -0.00 & -0.00 \\
\hline Shapley & & & & & 1.00 & -0.25 & -0.25 & -0.25 & -0.00 & -0.00 & -0.00 \\
\hline WCM-Power & & & & & & 1.00 & -0.25 & -0.25 & -0.00 & -0.00 & -0.00 \\
\hline $\begin{array}{l}\text { WCM- } \\
\text { Initiator }\end{array}$ & & & & & & & 1.00 & -0.25 & -0.00 & -0.00 & -0.00 \\
\hline ECM & & & & & & & & 1.00 & -0.00 & -0.00 & -0.00 \\
\hline Manufacturer & & & & & & & & & 1.00 & -0.50 & -0.50 \\
\hline LSP & & & & & & & & & & 1.00 & -0.50 \\
\hline Retailer & & & & & & & & & & & 1.00 \\
\hline
\end{tabular}

\subsection{Regression}

In Figure 3 the acceptance levels of the three parties over all gain sharing methods and phases are displayed for the business practitioners and the control group. Differences between the business practitioners and the control group can be observed. The total acceptance level of the business practitioners with $54.44 \%$ is significantly lower than the acceptance level of the control group with $64.44 \%$ even on a $1 \%$ significance level. Looking at each party individually, for both groups the LSPs show the highest acceptance rate and the retailers the lowest. For the control group, the manufacturers and the retailers show a higher acceptance level and the LSPs a slightly lower one compared to the business practitioners. Therefore, the differences between the parties are larger for the business practitioners. Nevertheless, for both groups a significant difference in the acceptance levels of the LSPs and the retailers compared to the manufacturers is observed on a $1 \%$ significance level, see Table 5. Moreover, for both groups the coefficient of the LSPs is positive. Therefore, in comparison to the baseline, the manufacturers, the LSPs have a significantly higher acceptance level on a $1 \%$ significance level. On the contrary, the retailers show for both groups a negative coefficient indicating a significantly lower acceptance level in comparison to the manufacturers even on a $1 \%$ significance level. 


\section{Business Practitioners}

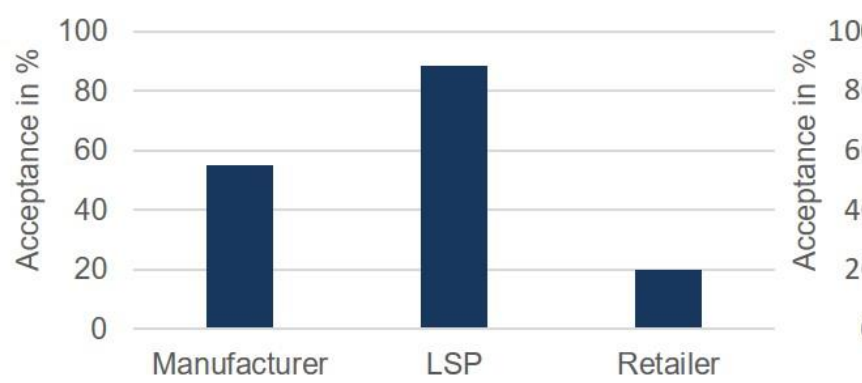

Control Group

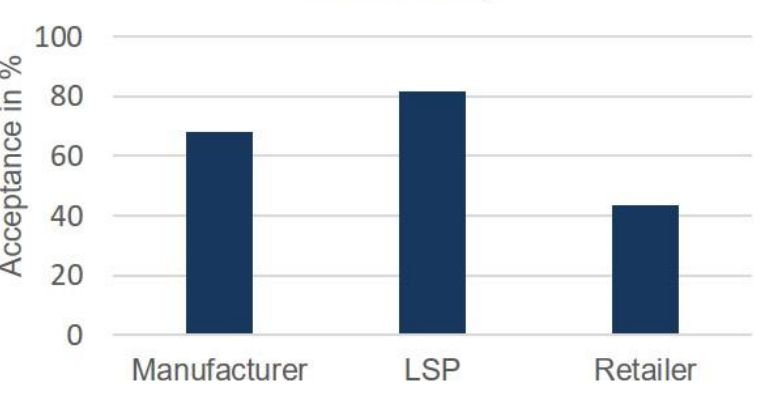

Figure 3: Acceptance levels of each of the three parties for the business practitioners and the control group

In Figure 4 the acceptance levels of each of the five different gain sharing methods in each of the three different phases for the business practitioners and the control group are displayed. For both groups the Nucleolus, the baseline, has the smallest acceptance rate with $44.44 \%$ for the business practitioners and $56.21 \%$ for the control group. This is also observed by the logistic regression, see Table 5. All gain sharing methods show a positive coefficient indicating that all methods compared to the baseline have a higher acceptance rate. However, only the ECM for the business practitioners and the Shapley value, the WCM-Power and the ECM for the control group show a significant increase in the acceptance levels. The most accepted method differs; the business practitioners prefer with an acceptance rate of $66.66 \%$ the ECM and the control group prefers the Shapley value with an acceptance rate of $71.24 \%$. Taken the phases into account, no significant difference between the phases is observed for the business practitioners, see Table 5. On the contrary, for the control group a significant decrease in the acceptance levels of Phase 2 in comparison to Phase 1 is identified, see Table 5.
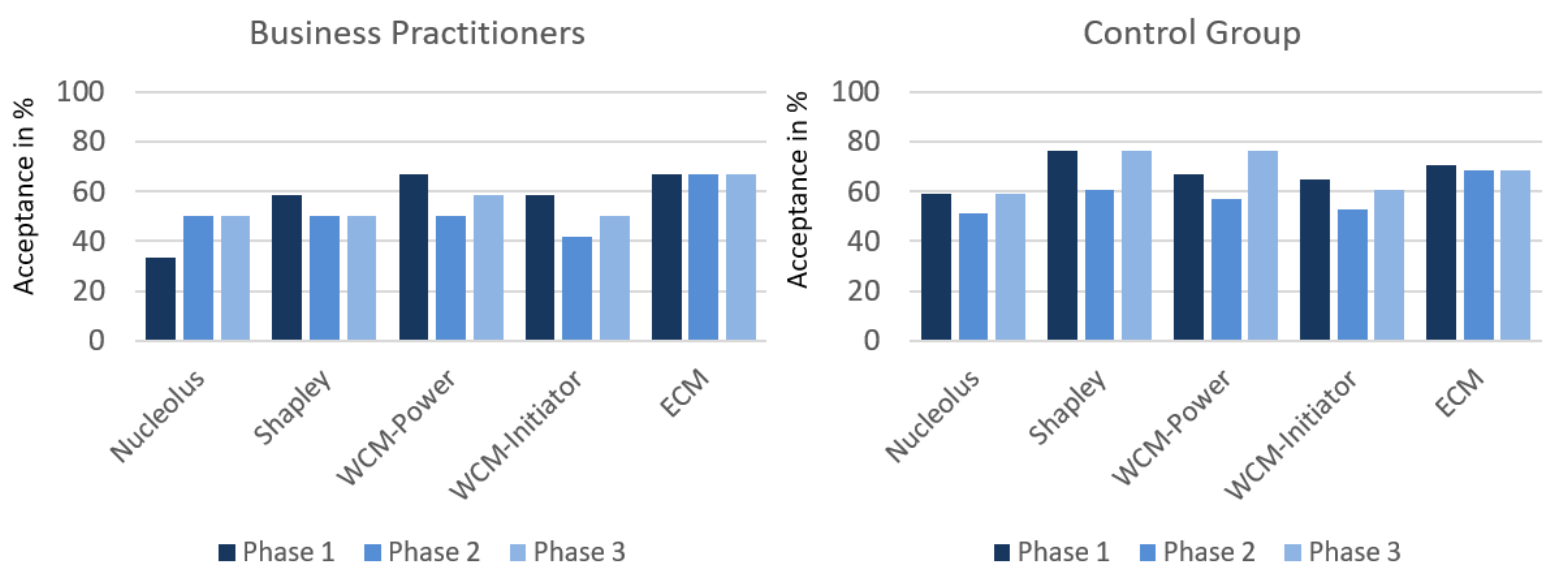

Figure 4: Acceptance levels for the five different gain sharing methods and the three different phases for the business practitioners and the control group 
Table 5: Logistic regression output for the regression of the business practitioners and the control group

\begin{tabular}{lllll}
\hline & \multicolumn{2}{l}{ Business Practitioners } & \multicolumn{2}{l}{ Control Group } \\
& Coefficient & Significance & Coefficient & Significance \\
\hline Intercept & -.242 & .633 & .515 & .029 \\
Shapley & .474 & .399 & .750 & .004 \\
WCM-Power & .790 & .161 & .508 & .045 \\
WCM-Initiator & .317 & .574 & .154 & .535 \\
ECM & 1.274 & .025 & .644 & .012 \\
Phase 2 & -.287 & .512 & -.465 & .019 \\
Phase 3 & -.096 & .827 & .039 & .848 \\
LSP & 1.769 & .000 & .768 & .000 \\
Retailer & -1.564 & .000 & -1.058 & .000 \\
\hline
\end{tabular}

\subsection{Regression Manufacturer}

In this section, the results of the acceptance levels for the manufacturers are presented. In Figure 5 the acceptance levels for the five different gain sharing methods in each of the three different phases are displayed for the business practitioners and the control group. For the manufacturers, the total acceptance rate of the control group is with $68.24 \%$ significantly higher compared to the acceptance rate of the business practitioners with $55 \%$. Both, the business practitioners and the control group, show differences in the acceptance levels between the methods. Moreover, both groups display an increase in the acceptance from the Nucleolus to the ECM. Therefore, the Nucleolus is the least accepted method with an acceptance level of $8.33 \%$ for the business practitioners and $25.49 \%$ for the control group. The most accepted method with an acceptance level of $100 \%$ for the business practitioners and $96.08 \%$ for the control group is the ECM. In Table 6 the results of the logistic regression are presented. A significant increase in the acceptance level of the gain sharing methods compared to the baseline is identified for the business practitioners and the control group.

Furthermore, a significant influence of the information availability on the acceptance levels of the business practitioners is observed. Compared to Phase 1, the acceptance levels in Phase 2 and Phase 3 are significantly lower, with the lowest acceptance rate in Phase 2. For the control group a significant negative influence on the acceptance level even on a $1 \%$ significance level is observed for Phase 2. 
Business Practitioners - Manufacturers

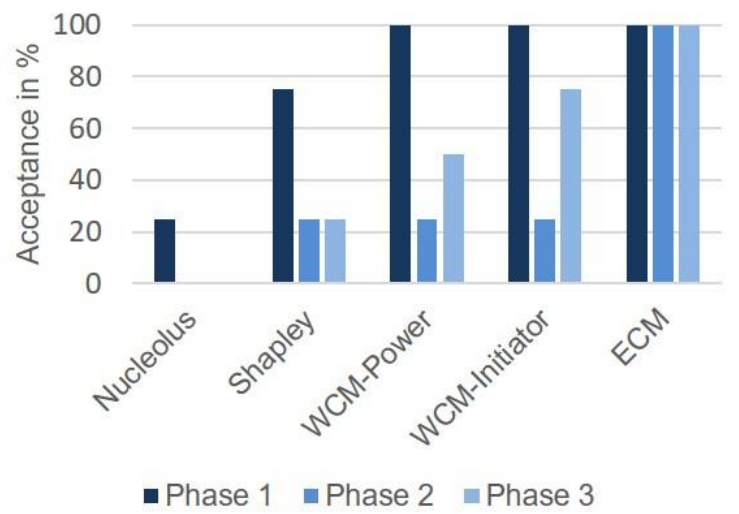

Control Group - Manufacturers

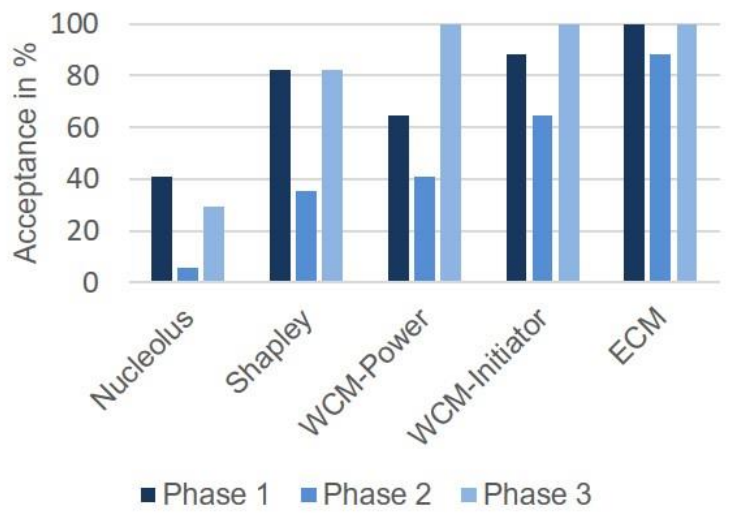

Figure 5: Acceptance levels of the five different gain sharing methods and three different phases for the manufacturer

Table 6: Logistic regression output for the manufacturers

\begin{tabular}{|c|c|c|c|c|}
\hline & \multicolumn{2}{|c|}{$\begin{array}{l}\text { Business Practitioners } \\
\text { - Manufacturers - }\end{array}$} & \multicolumn{2}{|c|}{$\begin{array}{l}\text { Control Group } \\
\text { - Manufacturers - }\end{array}$} \\
\hline & Coefficient & Significance & Coefficient & Significance \\
\hline Intercept & -.944 & .292 & -.929 & .395 \\
\hline Shapley & 2.355 & .037 & 2.183 & .000 \\
\hline WCM-Power & 3.239 & .003 & 2.299 & .000 \\
\hline WCM-Initiator & 3.665 & .001 & 3.402 & .000 \\
\hline ECM & 6.517 & .000 & 5.056 & .000 \\
\hline Phase 2 & -3.152 & .000 & -1.851 & .000 \\
\hline Phase 3 & -2.171 & .015 & .619 & .179 \\
\hline
\end{tabular}

\subsection{Regression LSP}

In this section, the results of the logistic regression for the LSPs are presented. In Figure 6 the acceptance levels for the five different gain sharing methods in each of the three different phases are displayed for the business practitioners and the control group. The control group has with $81.57 \%$ a lower total acceptance level compared to the business practitioners with $88.33 \%$. For the business practitioners, acceptance levels of $83.33 \%$ and higher for the different gain sharing methods are identified. The same holds for the control group. Except of the Nucleolus with an acceptance level of 
$68.63 \%$, acceptance levels of $80.39 \%$ and higher are observed. For the business practitioners and the control group differences in the acceptance levels between the phases are observed. A significant influence of the information availability on the acceptance levels of both groups is identified on a 10 $\%$ significance level. Another interesting finding is the positive influence of the information availability for the business practitioners and the negative influence for the control group. Moreover, for the control group a significant influence of the method on the acceptance levels compared to the Nucleolus is identified for all gain sharing methods except of the WCM-Power on a $10 \%$ significance level.
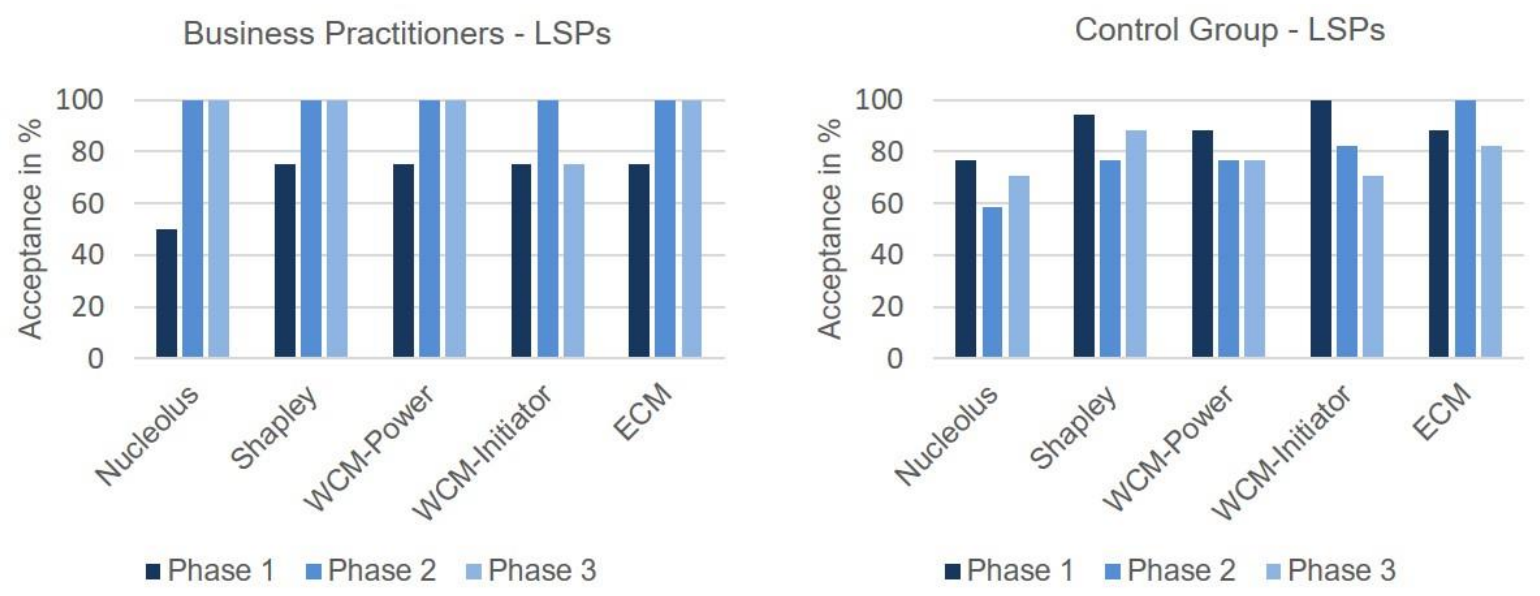

Figure 6: Acceptance levels of the five different gain sharing methods and three different phases for the $L S P$

Table 7: Logistic regression output for the LSPS

\begin{tabular}{lllll}
\hline & \multicolumn{2}{l}{$\begin{array}{l}\text { Business Practitioners } \\
- \text { LSPs - }\end{array}$} & & $\begin{array}{l}\text { Control Group } \\
- \text { LSPs - }\end{array}$ \\
& Coefficient & Significance & Coefficient & Significance \\
\hline Intercept & .296 & .719 & 1.407 & .001 \\
Shapley & .710 & .553 & 1.081 & .035 \\
WCM-Power & .710 & .553 & .646 & .170 \\
WCM-Initiator & .000 & 1.000 & .922 & .063 \\
ECM & .710 & .553 & 1.467 & .009 \\
Phase 2 & 2.757 & .010 & -.848 & .059 \\
Phase 3 & 1.644 & .050 & -.920 & .039 \\
\hline
\end{tabular}




\subsection{Regression Retailer}

In this section, the results of the retailer logistic regression are discussed. In Figure 7 the acceptance rates of the five different gain sharing methods in each of the three different phases are displayed for the business practitioners and the control group. In total, the retailers have a low acceptance level. Moreover, the business practitioners show a significantly lower acceptance rate with $20 \%$ compared to the control group with $43.53 \%$ even on a $1 \%$ significance level. For both groups, the retailers show a decrease in the acceptance from the Nucleolus to the ECM, with the lowest acceptance rate for the WCM-Initiator with no acceptance at all for the business practitioners and $9.8 \%$ for the control group. The highest acceptance rate can be assigned to the Nucleolus for both groups. The acceptance level for the Nucleolus with $74.51 \%$ for the control group is greater compared to the business practitioners with $41.67 \%$. For the business practitioners, a significant decrease in the acceptance rate compared to the Nucleolus is identified for the WCM-Initiator and the ECM on a 10 $\%$ significance level, see Table 8 . For the control group, a significant decrease is detected for all methods except for the Shapley value. In total, no significant influence of the phases is observed for the business practitioners and the control group, see Table 8 .
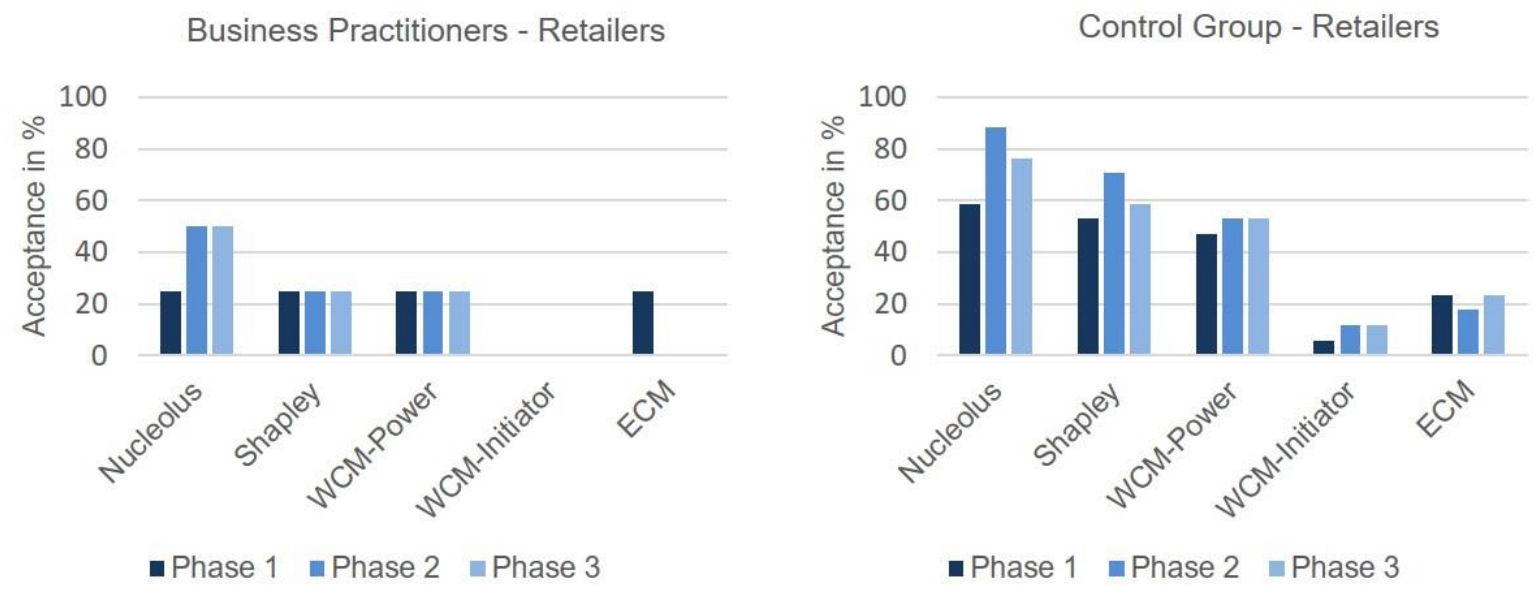

Figure 7: Acceptance levels of the five different gain sharing methods and three different phases for the retailer 
Table 8: Logistic regression output for the retailers

\begin{tabular}{lllll}
\hline & \multicolumn{2}{l}{$\begin{array}{l}\text { Business Practitioners } \\
\text { - Retailers - }\end{array}$} & & \multicolumn{2}{l}{ Control Group } \\
& Coefficient & Significance & Coefficient & Significance \\
\hline Intercept & -.296 & .675 & .769 & .041 \\
Shapley & -.659 & .418 & -.642 & .138 \\
WCM-Power & -.659 & .418 & -1.047 & .015 \\
WCM-Initiator & -2.830 & .014 & -3.328 & .000 \\
ECM & -1.666 & .075 & -2.393 & .000 \\
Phase 2 & .000 & 1.000 & .571 & .112 \\
Phase 3 & .000 & 1.000 & .381 & .287 \\
\hline
\end{tabular}

\section{Discussion}

\subsection{Result Discussion}

The results showed that the acceptance of gain sharing methods is influenced by the information availability and cognitive biases. The manufacturer is significantly negative influenced by the information availability for all phases except for Phase 3 for the control group. For both groups, a significant negative influence has been observed for Phase 2 even on a $1 \%$ significance level. In this phase, the manufacturers received the information that normally the lowest gain share has been assigned to them omitting the fact that they are the smallest player in the supply chain. Last information was only provided in Phase 3. This information increased the acceptance level compared to Phase 2; nevertheless, the acceptance level of Phase 3 is below the one of Phase 1. Moreover, results indicated a higher acceptance level of the control group compared to the business practitioners due to a higher acceptance level for the Nucleolus. The Nucleolus assigns a gain share of $4,333.33 €$ to the manufacturer. This gain share is higher than the manufacturer's contribution with $-5,000 €$. However, the business practitioners did not accept this method. Apart from one manufacturer who accepted the Nucleolus in Phase 1, the method was rejected. Considering the higher acceptance level of the control group, an impact of cognitive biases can be assumed for the business practitioners. The manufacturers had to invest the highest amount to start the SCC, see Table 2. Taken this into account, the manufacturer's reason for rejecting the gain sharing methods might be the small portion of the gain that cannot justify the costs and efforts. The LSPs have the highest acceptance rates. The acceptance level of the business practitioners amounts to $88.33 \%$ which is larger than the acceptance level of the control group. This can be explained by the influence of one cognitive bias, the so-called choice-supportive bias (Mather and Johnson, 2000). The LSPs are 
usually the party initiating to start the SCC in the Dutch FMCG industry. Therefore, no matter what gain share is assigned, the LSPs always show a high acceptance level. Further results indicate that the LSPs were positively influenced by information availability, whereas, the control group was negatively affected. Especially, for the WCM-Initiator a low acceptance level in Phase 2 and Phase 3 has been observed for the control group. The amount the LSPs received according to this method was the highest one. However, due to the low acceptance rate it is assumed that this amount has not been perceived as fair. The intention of the gain sharing method, namely that the party initiating to start the SCC receives the highest gain share, was not communicated. Moreover, it was not communicated that the LSP is the party who most of the time took the initiative to start the SCC. This might enhance the perception of unfairness. These findings indicate the importance of providing all relevant information. For the retailer, no significant influence of information availability has been identified. Further, a very low acceptance level with $20 \%$ for the business practitioners and $43.53 \%$ for the control group has been identified. Moreover, a significant difference in the acceptance levels between the business practitioners and the control group has been detected even on a $1 \%$ significance level. The acceptance level of the control group was more than twice of the business practitioners. The low acceptance rate of the two groups can be explained by the retailer's high contribution to the coalition gain combined with a lower gain according to all gain sharing methods, see Table 2 and Table 3. The significant difference between the business practitioners and the control group even on a $1 \%$ significance level as well as the missing influence of information availability on the acceptance levels indicate an additional influence of cognitive biases. One explanation might be the power of the retailers in the Dutch FMCG supply chain, identified by Jung et al. (2017b). Taking into account the power position of the retailers, this party might demand a bigger portion of the gain. Tijs and Driessen (1986) also outline that the choice of the method depends on the power feeling of the participants. The WCM-Power already considers the power position of a party; the highest weight was assigned to the retailers. However, the acceptance level of this method was also low. Based on this result, it is assumed that the weight did not represent the power of the retailer in the Dutch FMCG industry.

Due to the different influence of information availability and varying cognitive biases, no gain sharing method is preferred by all parties involved in the SCC. The manufacturers preferred the ECM with an acceptance level of $100 \%$. On the contrary, the retailers had a clear preference with $41.67 \%$ for the Nucleolus and the LSPs were indifferent between the Shapley value, the WCM-Power and the ECM. Except for the LSPs the same preferences were identified for the control group. The LSPs of the control group had a slight preference for the ECM. These findings demonstrate the challenge of applying a gain sharing method that is accepted by all parties involved in the SCC which is essential for the implementation and the success of a SCC (Cruijssen et al., 2007a; Cruijssen et al., 2007b; Cruijssen, 2012; Leng and Parlar, 2009). Further, only small differences between the acceptance levels of the gain sharing methods for all parties together could be identified and the acceptance levels were far from $100 \%$. The business practitioners have with an acceptance level of $66.67 \%$ a slight preference for the ECM. On the contrary, the control group has with an acceptance level of $71.24 \%$ a slight preference for the Shapley value. These findings confirm the result from literature that there exists no one preferred gain sharing method (Tijs and Driessen, 1986; Vanovermeire et al., 2014b).

\subsection{Theoretical Implications}

This paper is an extension of the work by Cruijssen et al. (2007a) and Leng and Parlar (2009). In their paper, Cruijssen et al. (2007a) identified the need for a fair gain allocation for the implementation and the success of horizontal SCCs. In the context of vertical SCC, Leng and Parlar (2009) confirmed 
the importance of a fair allocation method for parties to stay in the SCC. Although the acceptance of and satisfaction with a gain sharing method is necessary for a sustainable SCC, until now the acceptance of these gain sharing methods in practice has not been identified. Therefore, this paper enriches the SCM literature through the investigation of the acceptance levels of selected gain sharing methods in practice. Another contribution to the SCM literature is the integration of behavioural decision-making literature. The predominant assumption for a long time was that decision-makers are rational thinking agents. However, decision-makers are human beings and, therefore, the decision is influenced by the bounded rationality and cognitive biases (Schenk, 2011; Sterman, 1989; Simon, 1979). To ensure practical validity, it is necessary to incorporate behavioural research in studies (Tokar, 2010). In this paper, behavioural aspects were taken into account and, therefore, novel insights in the understanding of the acceptance of different gain sharing methods are provided. The influence of behavioural aspects such as information availability and cognitive biases on the acceptance of gain sharing methods has been identified.

\subsection{Practical implications}

Results showed that providing the same information to all parties involved in the SCC would lead to no preferred gain sharing method. As stated by Cruijssen et al. (2007a), a gain sharing method which is perceived as fair and is accepted by all parties involved in the SCC is crucial for the implementation and the success of the SCC. Therefore, one practical implication to overcome the barrier would be to provide all relevant information to each party individually. Further, differences between the business practitioners and the control group indicated the influence of various cognitive biases. Cognitive biases influence our rational behaviour resulting in unpredictable decisions (Schenk, 2011).

Therefore, in order to increase the predictability of the behaviour, one idea based on research by Soll et al. (2015) is to apply so-called debiasing-techniques. One debiasing-technique is to provide all relevant information packaged in an intuitively comprehensible and compelling format. A suggestion would be to show a figure which provides the information about the allocation of the gain.

\subsection{Further Research}

The present research offers several opportunities for further research. In the study, the participants of the online survey were all coming from one Dutch industry. Further research should include other geographical areas and/or a broader range of industries. Moreover, the participants of the online survey were confronted with only one specific artificial situation and no incentives were provided. Conducting the online survey in a real-life situation could identify other important behavioural decision-making aspects. Furthermore, additional gain sharing methods and weights should be considered. In the study four selected gain sharing methods have been tested; further research should also include gain sharing methods like the EPM or the WRSM in the survey. Only two weights were taking into account in the survey and the weights were determined based on interviews. For the retailer it has been identified that the chosen weight for the WCM-Power is not representing the reality. Further research should take into account also other important aspects of the FMCG industry and/or other industries as well as vary the weights assigned to the different parties. Finally, only a few behavioural decision-making aspects were taken into account and debiasing techniques have been proposed but not applied. Further research should also take into account other aspects. One example is the availability of time, which is another component of the bounded rationality mentioned by Simon (1979). The lack of available time force people to use heuristics or cognitive biases (Schenk, 2011; Simon, 1979), therefore, it is important to also include the availability of time in future surveys. Furthermore, debiasing techniques should be tested in practice. In total, it could be 
identified that due to the different influence of information availability and varying cognitive biases no gain sharing method is accepted by and satisfies all parties involved in a SCC. Further gain sharing methods should focus more on the participants' acceptance and satisfaction of the gain sharing methods. 


\section{References}

Allison, P.D. (2008), "Convergence Failures in Logistic Regression", SAS Global Forum, 2008.

Bailey, R. A. (2008), Design of Comparative Experiments, Cambridge University Press, Cambridge, UK.

Bendoly, E., Donohue, K. and Schultz, K.L. (2005), "Behavior in operations management: Assessing recent findings and revisiting old assumptions", Journal of Operations Management, Vol. 24 No. 6, pp. 1737-752.

Cao, M. and Zhang, Q. (2011), "Supply Chain Collaboration: Impact on collaborative advantage and firm performance", Journal of Operations Management, Vol. 29 No. 3, pp. 163-180.

Cruijssen, F. (2012), "Framework for collaboration - Collaboration concepts for CO-Modality $\left(\mathrm{CO}^{3}\right)^{\text {", }}$ $\mathrm{CO}^{3}$ position paper.

Cruijssen, F., Cools, M. and Dullaert, W. (2007a), "Horizontal cooperation in logistics; opportunities an impediments", Transportation Research E: Logistics and Transportation Review, Vol. 46 No. 3, pp. 129-142.

Cruijssen, F., Dullaert, W. and Fleuren, H. (2007b), "Horizontal Cooperation in Transport and Logistics: A Literature Review”, Transportation Journal, Vol. 46 No. 3, pp. 22-39.

Defryn, C., Vanovermeire, C. and Sörensen, K. (2016), "Gain Sharing in Horizontal Logistics Cooperation: A Case Study in the Fresh Fruit and Vegetables Sector", in Lu, M. and De Bock, J., Sustainable Logistics and Supply Chains, Springer, pp. 75-89.

De Martino, B., Kumaran, D., Seymour, B. and Dolan, R.J. (2006), "Frames, Biases, and Rational Decision-Making in the Human Brain", Science, Vol. 313 No. 5787, pp. 684-687.

De Kok, A.G., van Dalen, J. and van Hillegersberg, J. (Eds.) (2015), Cross-Chain Collaboration in the Fast Moving Consumer Goods Supply Chain, Eindhoven University of Technology, ISBN: 978-90-3863814-0.

Evans, J.E. and Mathur, A. (2005), "The value of online surveys", Internet Research, Vol. 15 No. 2, pp. 195-219. 
Firth, D. (1993), "Bias Reduction of Maximum Likelihood Estimates", Biometrika, Vol. 80 No. 1, pp. 27-38.

Frisk, M., Göthe-Lundgen, M., Jörnsten, K. and Rönnqvist, M. (2010), "Cost allocation in collaborative forest transportation", European Journal of Operational Research, Vol. 205 No. 2, pp. 448-458.

Greene, W.H. (2003), Econometric Analysis, second edition, A Wiley-Inter Science Publication.

Hallowell, M.R. and Gambarese, J.A. (2010), "Qualitative Research: Application of the Delphi Method to CEM Research", Journal of Construction Engineering and Management, Vol. 136 No. 1, pp. 99-107.

Heinze, G. and Schemper M. (2002), "A Solution to the Problem of Separation in Logistic Regression", Statistics in Medicine, Vol. 21 No. 16, pp. 2409-2419.

Homser, D.W. and Lemeshow, S. (2000), Applied Logistic Regression, Fifth edition, Person Education, New Jersey.

Jap, S.D. (2001), "'Pie Sharing" in Complex Collaboration Contexts", Journal of Marketing Research, Vol. 38 No. 1, pp. 86-99.

Jung, V., Peeters, M. and Vredeveld, T. (2017a), "Drivers and Resistors for Supply Chain Collaborations", in A. Fink, A. Fügenschuh and M.J. Geiger (Eds.), Operations Research Proceedings 2016. Selected Papers of the Annual International Conference of the German Operations Research Society (GOR), Helmut Schmidt University Hamburg, Germany, August 30 - September 2, 2016, Springer, pp. 623-628.

Jung, V., Peeters, M. and Vredeveld, T. (2017b), "A Framework for Better Evaluations of Supply Chain Collaborations: Evidence from the Dutch Fast Moving Consumer Goods Industry", working paper, Graduate School of the School of Business and Economics, Maastricht, 22 May.

Lambert, D.M., Emmelhainz, M.A. and Gardner, J.T. (1996). "Developing and Implementing Supply Chain Partnerships", The International Journal of Logistics Management, Vol. 7 No. 2, pp. 1-17.

Leng, M. and Parlar, M. (2005), "Game theoretic applications in supply chain management", InFor: Information Systems and Operational Research, Vol. 43 No. 3, pp. 187-220. 
Leng, M., Parlar, M. (2009), "Allocation of Cost Savings in a Three-Level Supply Chain with Demand Information Sharing: A Cooperative-Game Approach", Operations Research, Vol. 57 No. 1. pp. 200213.

Liu, P., Wu, Y. and Xu, N. (2010), "Allocating Collaborative Profit in Less-than Truckload Carrier Alliance", Journal Service Science \& Management, Vol. 3 No. 1, pp. 143-149.

Mantel, S.P., Tatikonda, M.V. and Liao, Y. (2006), "A Behavioral Study of Supply Manager Decisionmaking: Factors Influencing Make Versus Buy Evaluation", Journal of Operations Management, Vol. 24 No. 6, pp. 822-838.

Mather, M. and Johnson, M.K. (2000), "Choice-Supportive Source Monitoring: Do Our Decision Seem Better to Us as We Age?", Psychology and Aging, Vol. 15 No. 4, pp. 596-605.

Moulin, H. (1988), Axioms of Cooperative Decision Making, Econometric Society Monographs, Cambridge University Press.

Schenk, D.H. (2011), "Exploiting the Salience Bias in Designing Taxes", Yale Journal on Regulation, Vol. 28 No. 2, pp. 253-311.

Schmeidler, D. (1969), "The Nucleolus of a Characteristic Function Game", Journal on Applied Mathematics, Vol. 1 No. 6, pp. 1163-1170.

Shapley, L.S. (1953), "A Value for n-person Games", Annuals of Mathematics Studies, Vol. 28 No. 3, pp. 307-317.

Simatupang, T.M. and Sridharan, R. (2002), "The Collaborative Supply Chain", The International Journal of Logistics Management, Vol. 13 No. 1, pp. 15-30.

Simon, H.A. (1979), "Rational Decision Making in Business Organizations", The American Economic Review, Vol. 69 No. 4, pp. 493-513.

Sterman, J.D. (1989), "Modelling Managerial Behavior: Misperceptions of Feedback in a Dynamic Decision Making Experiment", Management Science, Vol. 35 No. 3, pp. 321-339.

Soll, J.B., Milkman, K.L. and Payne, J.W. (2015), "A User's Guide to Debiasing", in Keren, G. and Wu. G., The Wiley Blackwell Handbook of Judgment and Decision Making, Wiley Blackwell, pp. 924-951. 
Tversky, A. and Kahneman, D. (1981), "The framing of decisions and the psychology of choice", Science, Vol. 211 No. 4481, pp. 453-458.

Tijs, S.H. and Driessen, T.S.H. (1986), "Game theory and cost allocation problems", Management Science, Vol. 32 No. 8, pp. 1015-1028.

Tokar, T. (2010), "Behavioural research in logistics and supply chain management", The International Journal of Logistics Management, Vol. 21 No. 1, pp. 89-103.

Vanovermeire, C., Vercruysse, D. and Sörensen, K. (2014a), "Analysis of different cost allocation methods in collaborative transport settings", Journal of Engineering Management and Economics, Vol. 4 No. 2, pp. 132-150.

Vanovermeire, C., Sörensen, K., Van Breedam, A., Vannieuwenhuyse, B. and Verstrepen, S. (2014b), "Horizontal logistics collaboration: decreasing costs through flexibility and an adequate cost allocation strategy", International Journal of Logistics: Research and Applications, Vol. 17 No. 4, pp. 339-355. 


\section{Appendix}

\section{Appendix A}

The preliminary study consisted of 20 companies including 7 manufacturers, 6 LSPs and 7 retailers from the Dutch FMCG industry. All these companies were also participating in the logistics competition, which is observed in this paper. For the data collection individual, semi-structured interviews were conducted mostly face-to-face with the supply chain managers from the companies. The following questions concerning the gain sharing methods were asked to the interviewees:

- What does "fair gain sharing" mean for you and your company?

- To what extend are you willing to share gains among the entire supply chain? (answer on a 5point Likert scale)

- Would it be a problem for your company to share gains that are captured by your company, but are a result of a collaboration project with other parties involved? To what extend and why?

- If so, why are you willing to share gains? Mention your TOP 5.

- In your experience, how do other parties within your project/supply chain react to gain sharing?

- Before you start a collaboration project, is the transparency of how much each party needs to invest in collaboration projects an important issue?

- Before you are staring a collaboration project, is it crucial information for you to know how parties will benefit? To what extend and why? 


\section{Appendix B}

In the following an example of the online survey is presented. This is an online survey for a participant of the control group. The role of the participant is assigned to party A (manufacturer).

\section{Behavioral Study - Party A}

$$
1 / 23
$$

\section{Welcome to this behavioral study.}

Please be sure to answer the questions the same way you would act in a real-life situation. The questionnaire will take you through different scenarios. More information will be presented as the questionnaire progresses. Please note that it will not be possible to go back once a question is answered.

Thank you for participating in our survey.

Your role: Party A

Figure B.1: Example of the online survey

\section{Behavioral Study - Party A}

$3 / 23$

$13 \%$

\section{Collaboration Project X}

Imagine you are party A in a vertical supply chain that involves three different parties (party A, party B and party C). A new opportunity has presented itself in the form of a collaboration project: Project X.

The goal of this project is to take advantage of the extra benefits resulting from the collaboration by getting different parties (party A, party B, party C) involved to work together and optimize supply chain operations. It is expected that the parties involved require different investments and the distribution of gains over the supply chain will not be proportional.

You will be presented with your individual benefits (gains), costs and profits and with the overall supply chain profit once all parties enter the collaboration. Please investigate this information carefully.

Figure B.2: Example of the online survey

Figure B.3 to Figure B.5 show examples for the part of the online survey belonging to Phase 1 . In Figure B.5 an example for the question in Phase 1 is shown. In the online survey in total five questions were asked; one for each gain sharing method. 


\section{Collaboration Project X}

\begin{tabular}{|l|c|c|}
\hline & Party A & \\
\hline Benefits (expected gains) & $80,000 €$ & Party B \\
\hline Costs (investments) & $85,000 €$ & \\
\hline Direct profits & $-5,000 €$ & \\
\hline Overall collaboration profit & & \\
\hline
\end{tabular}

The benefit (expected gain) and costs (investments) presented are your individual direct benefits and investments for the project. The profit presented would be your direct profit in case no gain sharing methods are applied. The overall collaboration profit is the sum of all individual direct profits within the supply chain.

On the following pages, different gain sharing methods will be applied and a portion of the collaboration profit will be assigned to you. This assigned profit will replace your direct profit in the case of gain sharing.

Figure B.3: Example of the online survey

\section{Collaboration Project X}

Now you will be presented with different allocation scenarios for the supply chain profit resulting from the collaboration project. The allocation is the result of gain sharing methods that have been applied.

Please indicate whether you would accept or reject the presented solution.

Figure B.4: Example of the online survey 


\begin{tabular}{|l|c|c|}
\hline & Party A & Party B \\
\hline Benefits (expected gains) & $80,000 €$ & \\
\hline Costs (investments) & $85,000 €$ & \\
\hline Direct profits & $-5,000 €$ & \\
\hline Overall collaboration profit & & \\
\hline
\end{tabular}

Would you accept the following portion of the overall collaboration profit (replacing your direct profit)?

\section{$4,333 €$}

Accept

Reject

Figure B.5: Example of the online survey

Figure B.6 and Figure B.7 show examples for the part of the online survey belonging to Phase 2. In Figure B.7 an example for the question in Phase 2 is shown. In the online survey in total five questions were asked; one for each gain sharing method.

Behavioral Study - Party A

$11 / 23$ $48 \%$

\section{Collaboration Project X}

Now you will be presented with the same allocation scenarios for the supply chain profit resulting from the collaboration project; however, you will get a transparent overview of the benefits (gains), costs and profits of the other parties involved. The allocation is the result of the gain sharing methods that have been applied.

Please indicate whether you would accept or reject the presented solution.

Figure B.6: Example of the online survey 


\begin{tabular}{|l|c|c|c|}
\hline & Party A & Party B & Party C \\
\hline Benefits (expected gains) & $80,000 €$ & $50,000 €$ & $250,000 €$ \\
\hline Costs (investments) & $85,000 €$ & $10,000 €$ & $80,000 €$ \\
\hline Direct profits & $-5,000 €$ & $40,000 €$ & $170,000 €$ \\
\hline Profit allocation & $4,333 €$ & $55,333 €$ & $145,333 €$ \\
\hline Overall collaboration profit & \multicolumn{3}{|c|}{$205,000 €$} \\
\hline
\end{tabular}

Would you accept the following portion of the overall collaboration profit (replacing your direct profit)?

\section{$4,333 €$}

Accept

Reject

Figure B.7: Example of the online survey

Figure B.8 to Figure B.10 show examples for the part of the online survey belonging to Phase 3 . In Figure B.10 an example for the question in Phase 3 is shown. In the online survey in total five questions were asked; one for each gain sharing method.

\section{Collaboration Project $\mathrm{X}$}

Now you will be presented with the same allocation scenarios for the supply chain profit resulting from the collaboration project; however, you now not only get a transparent overview of the benefits (gains), costs and profits of the other parties involved, but also an idea of the market conditions. The allocation is the result of gain sharing methods that have been applied.

Please indicate whether you would accept or reject the presented solution. 
Figure B.8: Example of the online survey

Behavioral Study - Party A

$18 / 23$

$78 \%$

\section{Project X Assumptions}

Party $\mathrm{C}$ is the biggest player on the market with a market share of $25 \%$ and is a member of a union called "Super Unie". Relationships with this party are important.

Party $B$ is a medium player on the market with a market share of $10 \%$

Party A is based locally (not international) and the goods are relatively easy to substitute. Party A is not a member of any association or union of parties from the same position in the supply chain.

Figure B.9: Example of the online survey

Behavioral Study - Party A

$19 / 23$ $83 \%$

\begin{tabular}{|c|c|c|c|c|}
\hline & Party A & Party B & Party C & \multirow{6}{*}{$\begin{array}{l}\text { Party } \mathrm{C} \text { is the biggest player on the market with a market share of } 25 \% \\
\text { and is a member of a union called "Super Unie". Relationships with this } \\
\text { party are important. } \\
\text { Party B is a medium player on the market with a market share of } 10 \% \text {. } \\
\text { Party A is based locally (not international) and the goods are relatively } \\
\text { easy to substitute. Party A in not a member of any association or union of } \\
\text { parties from the same position in the supply chain. }\end{array}$} \\
\hline Benefits (expected gains) & $80,000 €$ & $50,000 €$ & $250,000 €$ & \\
\hline Costs (investments) & $85,000 €$ & $10,000 €$ & $80,000 €$ & \\
\hline Direct profits & $-5,000 €$ & $40,000 €$ & $170,000 €$ & \\
\hline Profit allocation & $4,333 €$ & $55,333 €$ & $145,333 €$ & \\
\hline Overall collaboration profit & \multicolumn{3}{|c|}{$205,000 €$} & \\
\hline
\end{tabular}

Would you accept the following portion of the overall collaboration profit (replacing your direct profit)?

\section{$4,333 €$}

Accept

Reject

Figure B.10: Example of the online survey 


\section{Appendix C}

In the following tables, the correlation matrices for all performed logistic regressions are shown.

Table C.1 presents the correlation matrices of the business practitioners and Table C. 2 and Table C. 3 the correlation matrices of the control group.

Table C.1: Correlation matrix of the manufacturer, the LSP and the retailer regression of the business practitioners

\begin{tabular}{|c|c|c|c|c|c|c|c|c|}
\hline & Phase 1 & Phase 2 & Phase 3 & Nucleolus & Shapley & $\begin{array}{l}\text { WCM- } \\
\text { Power }\end{array}$ & $\begin{array}{l}\text { WCM- } \\
\text { Initiator }\end{array}$ & ECM \\
\hline Phase 1 & 1.00 & -0.50 & -0.50 & -0.00 & -0.00 & -0.00 & -0.00 & -0.00 \\
\hline Phase 2 & & 1.00 & -0.50 & -0.00 & -0.00 & -0.00 & -0.00 & -0.00 \\
\hline Phase 3 & & & 1.00 & -0.00 & -0.00 & -0.00 & -0.00 & -0.00 \\
\hline Nucleolus & & & & 1.00 & -0.25 & -0.25 & -0.25 & -0.25 \\
\hline Shapley & & & & & 1.00 & -0.25 & -0.25 & -0.25 \\
\hline WCM-Power & & & & & & 1.00 & -0.25 & -0.25 \\
\hline WCM-Initiator & & & & & & & 1.00 & -0.25 \\
\hline ECM & & & & & & & & 1.00 \\
\hline
\end{tabular}


Table C.2: Correlation matrix of the regression of the control group

\begin{tabular}{|c|c|c|c|c|c|c|c|c|c|c|c|}
\hline & $\begin{array}{l}\text { Phase } \\
1\end{array}$ & $\begin{array}{l}\text { Phase } \\
2\end{array}$ & $\begin{array}{l}\text { Phase } \\
3\end{array}$ & Nucleolus & Shapley & $\begin{array}{l}\text { WCM- } \\
\text { Power }\end{array}$ & $\begin{array}{l}\text { WCM- } \\
\text { Initiator }\end{array}$ & ECM & $\begin{array}{l}\text { Manufac- } \\
\text { turer }\end{array}$ & LSP & Retailer \\
\hline Phase 1 & 1.00 & -0.50 & -0.50 & -0.00 & 0.00 & 0.00 & -0.00 & -0.00 & -0.00 & -0.00 & -0.00 \\
\hline Phase 2 & & 1.00 & -0.50 & -0.00 & -0.00 & -0.00 & -0.00 & 0.00 & -0.00 & -0.00 & -0.00 \\
\hline Phase 3 & & & 1.00 & -0.00 & 0.00 & 0.00 & -0.00 & 0.00 & -0.00 & -0.00 & -0.00 \\
\hline Nucleolus & & & & 1.00 & -0.25 & -0.25 & -0.25 & -0.25 & -0.00 & -0.00 & -0.00 \\
\hline Shapley & & & & & 1.00 & -0.25 & -0.25 & -0.25 & -0.00 & -0.00 & -0.00 \\
\hline WCM-Power & & & & & & 1.00 & -0.25 & -0.25 & 0.00 & -0.00 & -0.00 \\
\hline $\begin{array}{l}\text { WCM- } \\
\text { Initiator }\end{array}$ & & & & & & & 1.00 & -0.25 & -0.00 & 0.00 & 0.00 \\
\hline ECM & & & & & & & & 1.00 & 0.00 & -0.00 & 0.00 \\
\hline Manufacturer & & & & & & & & & 1.00 & -0.50 & -0.50 \\
\hline LSP & & & & & & & & & & 1.00 & -0.50 \\
\hline Retailer & & & & & & & & & & & 1.00 \\
\hline
\end{tabular}


Table C.3: Correlation matrix of the manufacturer, the LSP and the retailer regression of the control group

\begin{tabular}{|c|c|c|c|c|c|c|c|c|}
\hline & Phase 1 & Phase 2 & Phase 3 & Nucleolus & Shapley & $\begin{array}{l}\text { WCM- } \\
\text { Power }\end{array}$ & $\begin{array}{l}\text { WCM- } \\
\text { Initiator }\end{array}$ & ECM \\
\hline Phase 1 & 1.00 & -0.50 & -0.50 & -0.00 & -0.00 & 0.00 & 0.00 & 0.00 \\
\hline Phase 2 & & 1.00 & -0.50 & -0.00 & -0.00 & 0.00 & 0.00 & 0.00 \\
\hline Phase 3 & & & 1.00 & -0.00 & 0.00 & 0.00 & 0.00 & 0.00 \\
\hline Nucleolus & & & & 1.00 & -0.25 & -0.25 & -0.25 & -0.25 \\
\hline Shapley & & & & & 1.00 & -0.25 & -0.25 & -0.25 \\
\hline WCM-Power & & & & & & 1.00 & -0.25 & -0.25 \\
\hline WCM-Initiator & & & & & & & 1.00 & -0.25 \\
\hline ECM & & & & & & & & 1.00 \\
\hline
\end{tabular}

